\title{
Inhibition of Cocaine Sensitization by MK-801, a Noncompetitive $N$-Methyl-D-Aspartate (NMDA) Receptor Antagonist: Evaluation by Ambulatory Activity in Mice
}

\author{
Iturou Ida ${ }^{1}$, Takayasu Asami ${ }^{2}$ and Hisashi Kuribara ${ }^{3}$ \\ ${ }^{I}$ Department of Neuropsychiatry, Gunma University School of Medicine, 3-39-22 Showa-machi, Maebashi 371, Japan \\ ${ }^{2}$ Gunma Prefectural Sawa Hospital of Psychiatry, 2374 Ohaza-Kunisada, Azuma-mura, Sawa-gun, Gunma 379-22, Japan \\ ${ }^{3}$ Department of Neurobiology and Behavior, Behavior Research Institute, Gunma University School of Medicine, \\ 3-39-22 Showa-machi, Maebashi 371, Japan
}

Received December 26, 1994 Accepted July 3, 1995

\begin{abstract}
Alterations of cocaine effects, which were induced by prior repeated 5-time administration of MK-801 ((+)-5-methyl-10,11-dihydro-5H-dibenzo[a,d]cyclohepten-5,10-imine) (i.p.) alone or in combination with cocaine (s.c.) at 3- to 4-day intervals, were investigated by means of ambulatory activity in mice. The repeated administration of either cocaine $(10$ and $20 \mathrm{mg} / \mathrm{kg})$ alone or MK-801 $(0.3 \mathrm{mg} / \mathrm{kg})$ alone progressively enhanced each drug's effect. The enhanced effects of cocaine and MK- 801 were estimated to be 1.8-2.2 times and about 1.4 times, respectively, as great as those at the 1st administration. Although the coadministration of MK- 801 with cocaine produced a significant enhancement in the ambulation-increasing effect, the comparatively higher doses of MK- $801(0.3$ and $1 \mathrm{mg} / \mathrm{kg})$ acted not only to reduce cocaine sensitivity but also to inhibit the development of cocaine sensitization. Thus, the mice that had been given MK-801 $(0.3$ and $1 \mathrm{mg} / \mathrm{kg})$ alone 5 times showed lower sensitivities to cocaine $(20 \mathrm{mg} / \mathrm{kg})$ than the mice given saline alone. The mice coadministered MK-801 $(0.3$ and $1 \mathrm{mg} / \mathrm{kg})$ with cocaine $(10 \mathrm{and} 20 \mathrm{mg} / \mathrm{kg})$ also exhibited lower sensitivities to cocaine $(10$ and $20 \mathrm{mg} / \mathrm{kg})$ than those given cocaine alone. However, MK-801 could not ameliorate the established sensitization to cocaine. Similar interactions have been demonstrated between MK- 801 at $1 \mathrm{mg} / \mathrm{kg}$, but not $0.3 \mathrm{mg} / \mathrm{kg}$, and methamphetamine. The present results indicate that MK- 801 can inhibit the development of sensitization to cocaine at a lower dose than that required to inhibit methamphetamine sensitization.
\end{abstract}

Keywords: MK-801, Ambulatory activity, Repeated administration, Cocaine sensitization, Drug interaction

MK-801, a potent and selective noncompetitive $N$ methyl-D-aspartate (NMDA) antagonist, possesses anticonvulsant potential $(1,2)$, the protective ability against neural cell loss from ischemia (3) or hypoglycemia (4), anticonflict effects $(5,6)$ and ambulation-increasing effects $(7,8)$. Because evidence indicates that many neuropsychiatric diseases are mediated by the NMDA subtype of excitatory receptor (9), there is considerable interest in the psychopharmacological and behavioral effects of MK-801.

It is well-known that the repeated administration of CNS stimulants, such as amphetamines and cocaine, produces the sensitization to their ambulation-increasing and/or stereotypy-producing effects $(10,11)$. Behavioral sensitization has been considered to be an animal model of the psychoses induced by amphetamine- and cocaine-abuse.
MK-801 increases the ambulatory activity of rats through the activation of the central dopaminergic system (12). In our previous study (13), the coadministration of MK-801 with methamphetamine potentiated the ambulation-increasing effect. However, a comparatively higher dose of MK-801 $(1 \mathrm{mg} / \mathrm{kg})$ rather inhibited the development of sensitization to methamphetamine. The behavioral characteristics of cocaine as a CNS stimulant was similar to those of amphetamines. The interactions between MK-801 and cocaine have been evaluated in the behaviors of rats, but not in those of mice (14-16).

Hence, this study examined the modification of cocaine sensitization by MK-801 through the observation of ambulatory activity in mice. MK-801 was administered prior to, simultaneously with, or after the repeated administration of cocaine. 


\section{MATERIALS AND METHODS}

\section{Animals}

Male mice of the ddY strain (Japan Laboratory Animal, Tokyo), 7-weeks-old, were used. Before the start of and during the experiment, they were group-housed in standard cages of $25 \mathrm{D} \times 15 \mathrm{~W} \times 15 \mathrm{H} \mathrm{cm}(10 \mathrm{mice} /$ cage $)$ and allowed free access to a solid diet (MF; Oriental Yeast, Tokyo) and tap water. The breeding room was controlled so that the light-dark schedule (lighting time: 6:00-18:00 $\mathrm{hr})$ and temperature $\left(23 \pm 1^{\circ} \mathrm{C}\right)$ were almost constant.

\section{Apparatus}

The mouse's ambulatory activity was measured with a tilting-type ambulometer (AMB-10; O'hara \& Co., Tokyo). The apparatus consisted of 10 bucket-like activity cages, each of which was made of Plexiglas and had a diameter of $20 \mathrm{~cm}$. Thereby, the ambulatory activities of 10 individual mice could be measured at the same time.

\section{Drugs}

The drug used were MK-801 ((+)-5-methyl-10,11-dihydro- $5 H$-dibenzo $[a, d]$ cyclohepten-5,10-imine hydromaleate) (Merck/Banyu, Tokyo) and cocaine $\mathrm{HCl}$ (Takeda Chem., Osaka). These drugs were dissolved in physiological saline, and the concentration of each drug solution was adjusted so that each volume administered was constant at $0.1 \mathrm{ml} / 10 \mathrm{~g}$ body weight. MK-801 and cocaine were administered intraperitoneally (i.p.) and subcutaneously (s.c.), respectively.

\section{Experimental procedures}

Repeated administrations of cocaine alone: Two groups of mice $(\mathrm{N}=10-30)$ were treated with the repeated 5-time administrations of cocaine ( $10 \mathrm{or} 20 \mathrm{mg} / \mathrm{kg}$ ) at 3- to 4-day intervals. The ambulation of the mouse was measured $3 \mathrm{hr}$ after each administration. Four days after the 5th administration, these mice were administered the same doses of cocaine. The other two groups of mice $(\mathrm{N}=10-30)$ were given saline 5 times in the same way as in the cocaine treatment. Four days after the 5 th saline administration, these mice were administered cocaine (10 or $20 \mathrm{mg} / \mathrm{kg}$ ). The drug-naive mice ( 2 groups) were also given cocaine ( 10 or $20 \mathrm{mg} / \mathrm{kg}$ ).

Repeated administrations of MK-801 alone and challenge-administration of cocaine: Four groups of mice $(\mathrm{N}=20-30)$ were treated with repeated 5 -time administrations of MK-801 (0: physiological saline, $0.1,0.3$ and $1 \mathrm{mg} / \mathrm{kg}$ ) at 3- to 4-day intervals. Four days after the 5 th administration of MK-801, cocaine $(20 \mathrm{mg} / \mathrm{kg})$ was challenge-administered to all of these mice.

Repeated coadministrations of $M K-801$ with cocaine:
Eight groups of mice $(\mathrm{N}=9-20)$ were treated with 5-time repeated coadministrations of MK-801 $(0,0.1,0.3$ and 1 $\mathrm{mg} / \mathrm{kg}$ ) with cocaine (10 and $20 \mathrm{mg} / \mathrm{kg}$ ) at 3- to 4-day intervals. Seven days after the 5 th coadministration, these mice were challenge-administered cocaine (10 and 20 $\mathrm{mg} / \mathrm{kg}$ ).

Repeated treatments with $M K-801$ after cocaine sensitization: Four groups of mice $(\mathrm{N}=19-20)$ were first repeatedly given cocaine $(20 \mathrm{mg} / \mathrm{kg})$ at 3- to 4 -day intervals to induce sensitization to the ambulation-increasing effect. From the next day after the final cocaine administration, these mice were given MK-801 $(0,0.1,0.3$ and 1 $\mathrm{mg} / \mathrm{kg}$ ) daily for 5 days, and then all of these mice were readministered cocaine alone 7 days after the last dose of MK-801.

All the experiments were carried out between 9:00 $-17: 00 \mathrm{hr}$.

\section{Statistical analyses}

The mean overall ambulatory activity counts for $3 \mathrm{hr}$ after the drug administration were calculated in individual groups of mice. These data were first analyzed by one-way and/or two-way ANOVA. If there were significant overall effects, comparisons between individual data were carried out by Dunnett's test. When P values were equal to or less than 0.05 , they were defined as significantly different.

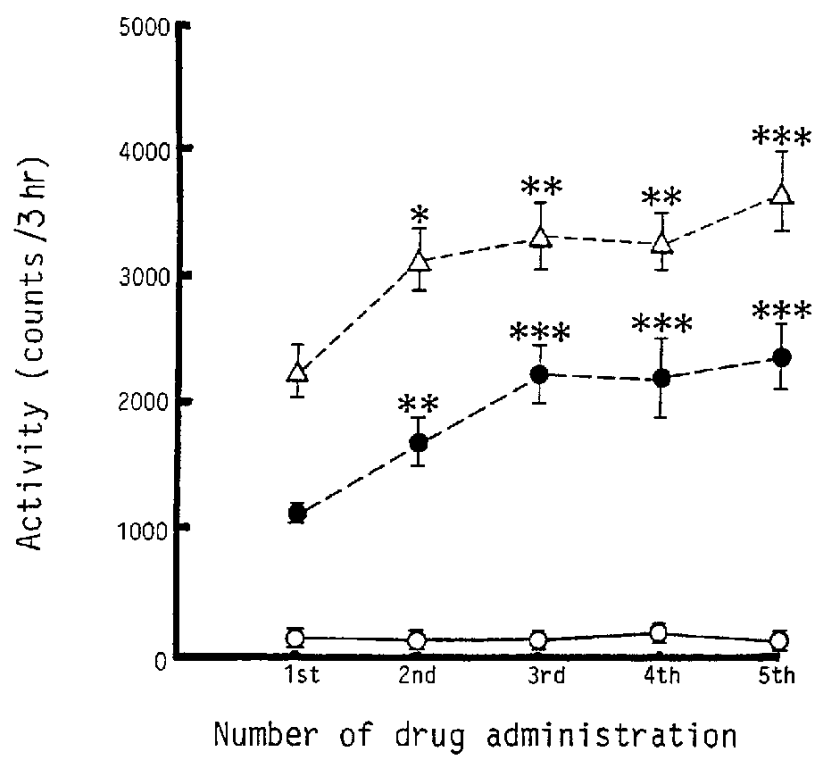

Fig. 1. Changes in the mean 3-hr overall ambulatory activity counts after the repeated 5-time s.c. administrations of saline $(O)$; cocaine, $10 \mathrm{mg} / \mathrm{kg}(\bigcirc)$; and cocaine, $20 \mathrm{mg} / \mathrm{kg}(\triangle)$ at 3- to 4-day intervals. Values are expressed as the mean \pm S.E. ${ }^{*}, * *$ and $* * *$ : Significantly different from the activity counts at the 1st administration within the group $(P<0.05, P<0.01$ and $P<0.001$, respectively). $\mathrm{N}=10-30$ in each group. 


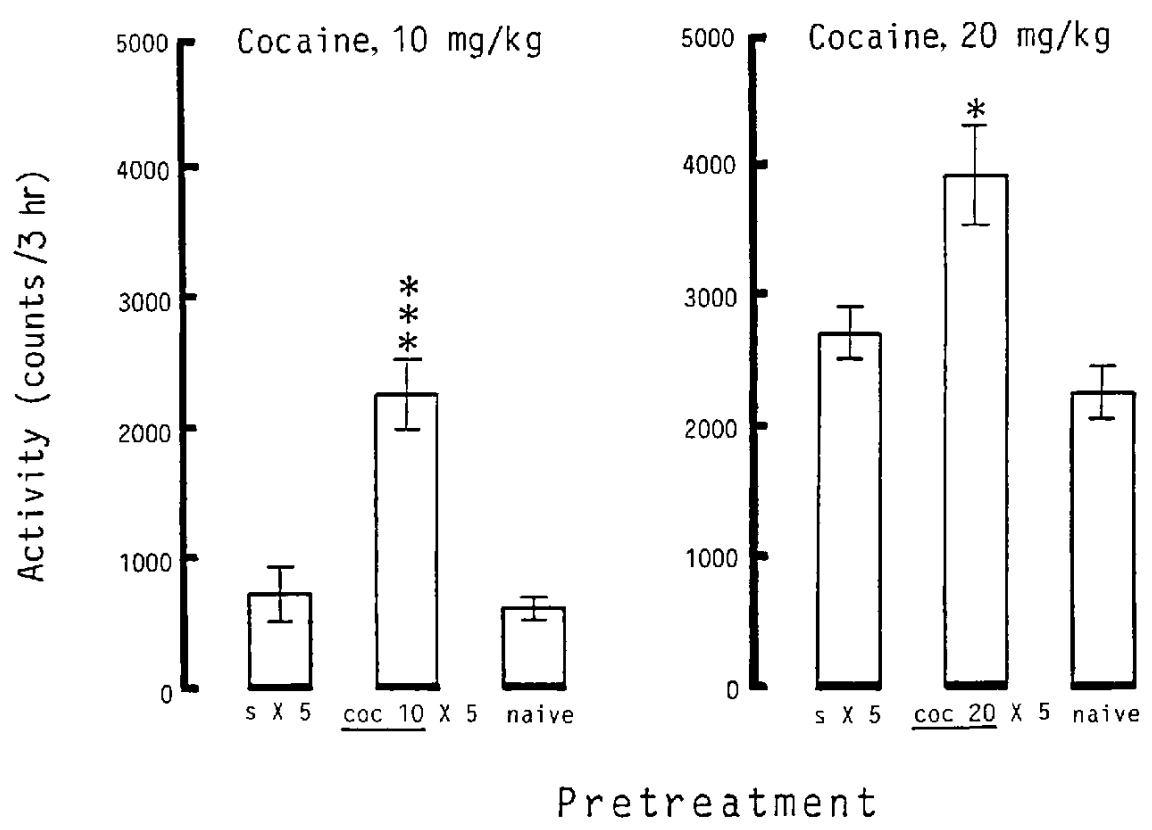

Fig. 2. Overall activity counts for $3 \mathrm{hr}$ after the challenge-administration of cocaine $(10 \mathrm{and} 20 \mathrm{mg} / \mathrm{kg}$, s.c.) to the mice that have been given the repeated 5-time s.c. administrations of saline (s) and cocaine (coc: 10 and $20 \mathrm{mg} / \mathrm{kg}$ ) and those after the challenge to the drug-naive mice. The challenge administration was conducted 4 days after the 5 th treatment. Values are expressed as the mean \pm S.E. ${ }^{*}$ and ${ }^{* * *}$ : Significantly different from the activity counts of the saline-administered mice $(\mathbf{P}<0.05$ and $\mathrm{P}<0.001$, respectively). $\mathrm{N}=\mathbf{1 0 - 3 0}$ in each group.

\section{RESULTS}

\section{Effects of repeated administrations of cocaine alone}

As shown in Fig. 1, repeated administrations of cocaine produced a sensitization to the ambulation-increasing effect $[\mathrm{F}($ dose $)=188.25, \mathrm{P}<0.001 ; \mathrm{F}$ (administration) $=7.48, P<0.001 ;$ and $F($ dose $\times$ administration $)=1.30$, n.s.]. The activity counts at the $2 \mathrm{nd}-5$ th administrations of cocaine (10 and $20 \mathrm{mg} / \mathrm{kg}$ ) were significantly higher than those at the 1st administration. On the other hand, the repeated administrations of saline elicited no significant change in the ambulatory activity throughout the 5time administrations.

As shown in Fig. 2, the saline-administered control mice showed no significant change in the sensitivity to cocaine. The activity counts of the cocaine-administered mice were significantly higher than those of the controls.

\section{Effects of repeated administrations of $M K-801$ alone}

As shown in Fig. 3, MK-801 increased the activity in a dose-dependent manner $[\mathrm{F}($ dose $)=247.46, \quad \mathrm{P}<0.001]$. However, ANOVA revealed that the repeated administrations of MK-801 produced no significant alteration in the effect $[\mathrm{F}(\mathrm{administration})=0.81$, n.s. $]$. There was a significant relationship between dose and administration $[\mathrm{F}($ dose $\times$ administration $)=1.95, \mathrm{P}<0.05]$. The individual comparison revealed that MK-801 $(0.3 \mathrm{mg} / \mathrm{kg})$ produced a slight sensitization to its ambulation-increasing effect, and the activity count at the 5th administration was significantly higher than that at the 1st administration. On the other hand, the repeated administrations of $\mathrm{MK}-801$, at 0.1 and $1 \mathrm{mg} / \mathrm{kg}$, produced no significant change in their effects.

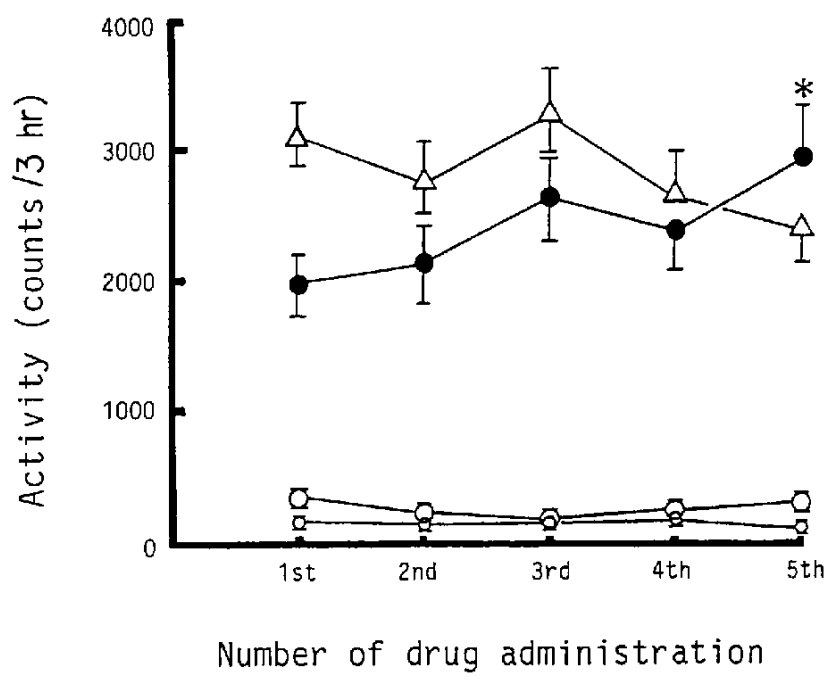

Fig. 3. Changes in the mean 3-hr overall ambulatory activity counts after the repeated 5 -time i.p. administrations of saline $(0)$ or MK-801 [0.1 $\bigcirc), 0.3(\bigcirc)$ and $1 \mathrm{mg} / \mathrm{kg}(\triangle)]$ at 3- to 4-day intervals. Values are expressed as the mean \pm S.E. *: Significantly different from the activity counts at the 1 st administration within the group $(P<0.05) . N=20-30$ in each group. 


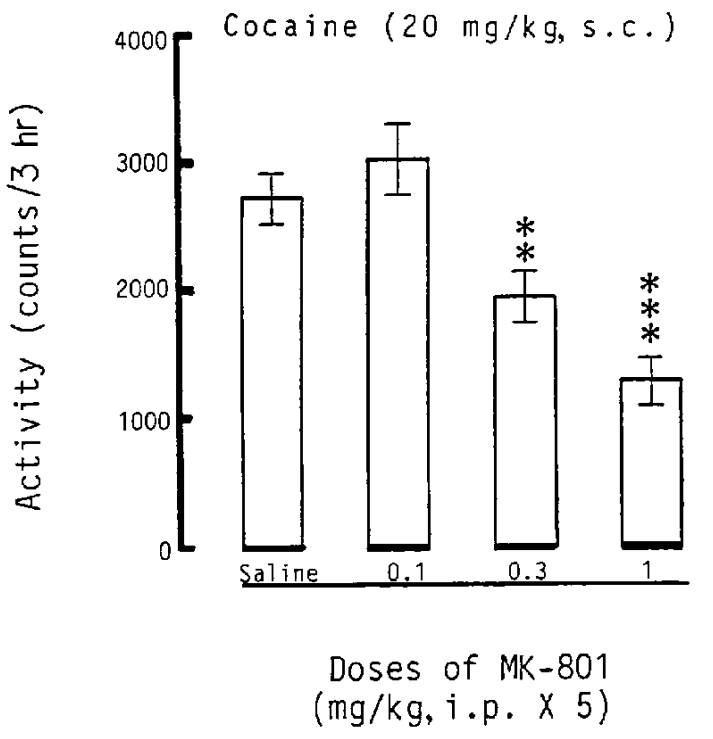

Fig. 4. Overall activity counts for $3 \mathrm{hr}$ after the challenge-administration of cocaine $(20 \mathrm{mg} / \mathrm{kg}$, s.c. $)$ to the mice that have been given the repeated 5-time administrations of saline or MK-801. Values are expressed as the mean \pm S.E. ${ }^{* *}$ and ${ }^{* * *}$ : Significantly different from the activity counts of the saline-administered mice $(P<0.01$ and $\mathrm{P}<0.001$, respectively). $\mathrm{N}=20-30$ in each group.

As shown in Fig. 4, the repeated treatment with MK801 elicited a dose-dependent decrease in the sensitivity of mice to challenge cocaine $[\mathrm{F}(\mathrm{dose})=10.69, \mathrm{P}<0.01]$. The decrement in the cocaine-sensitivity was significant in the mice given 0.3 and $1 \mathrm{mg} / \mathrm{kg}$ of MK-801. MK-801 at 0.1 $\mathrm{mg} / \mathrm{kg}$ had no such effect.

\section{Effects of coadministrations of $M K-801$ with cocaine}

As shown in Fig. 5, at the 1st coadministration of MK801 with cocaine, the ambulation-increasing effect was potentiated. The repeated coadministrations of MK-801 with cocaine produced significant modifications in the ambulation-increasing effect: for MK-801 with cocaine $(10 \mathrm{mg} / \mathrm{kg}) \quad[\mathrm{F}($ dose $)=95.23, \quad \mathrm{P}<0.001 ; \mathrm{F}$ (administration $)=2.36$, n.s.; and $F($ dose $\times$ administration $)=1.50$, n.s.] (upper panel) and for MK-801 with cocaine (20 $\mathrm{mg} / \mathrm{kg}) \quad[\mathrm{F}($ dose $)=14.48, \quad \mathrm{P}<0.001 ; \mathrm{F}$ (administration) $=6.84, \mathrm{P}<0.001 ;$ and $\mathrm{F}($ dose $\times$ administration $)=3.21$, $\mathrm{P}<0.001]$. When the coadministrations of MK-801 $(0.1$ $\mathrm{mg} / \mathrm{kg})$ with cocaine $(10 \mathrm{mg} / \mathrm{kg})$ and MK-801 $(0.1$ and $0.3 \mathrm{mg} / \mathrm{kg})$ with cocaine $(20 \mathrm{mg} / \mathrm{kg})$ were repeated, the ambulation-increasing effects became further enhanced in proportion to the number of administrations. However, the coadministrations of MK-801 $(0.3$ and $1 \mathrm{mg} / \mathrm{kg})$ with cocaine $(10 \mathrm{mg} / \mathrm{kg})$ and MK-801 $(1 \mathrm{mg} / \mathrm{kg})$ with cocaine $(20 \mathrm{mg} / \mathrm{kg})$ reproduced almost the same effects throughout the 5-time administrations.

As shown in Fig. 6, the repeated coadministrations of

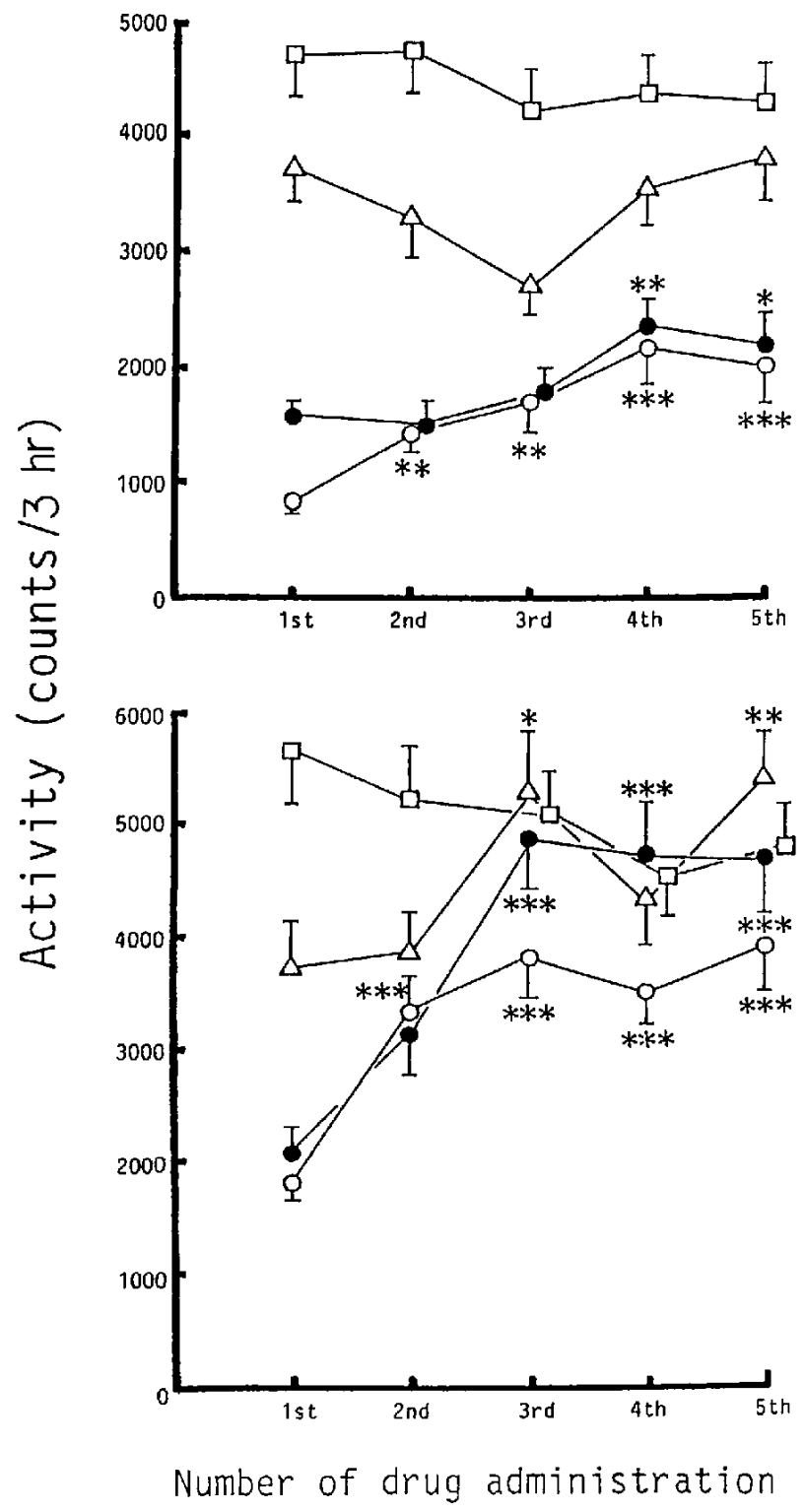

Fig. 5. Changes in the mean 3-hr overall ambulatory activity counts after the repeated 5-time i.p. administrations of saline $(\bigcirc)$ or MK-801 $[0.1(\bigcirc), 0.3(\triangle)$ and $1 \mathrm{mg} / \mathrm{kg}(\square)]$ in combination with s.c. administration of cocaine, $10 \mathrm{mg} / \mathrm{kg}$ (upper panel) and 20 $\mathrm{mg} / \mathrm{kg}$ (lower panel), at 3- to 4-day intervals. Values are expressed as the mean \pm S.E. ${ }^{* * *}$ and $* * *$ : Significantly different from the activity counts at the 1 st administration within the group $(\mathrm{P}<0.05$, $\mathrm{P}<0.01$ and $\mathrm{P}<0.001$, respectively). $\mathrm{N}=9-20$ in each group.

MK-801 with cocaine elicited a significant decrease in the sensitization to cocaine [for cocaine $(10 \mathrm{mg} / \mathrm{kg})$ : $\mathrm{F}($ dose $)=10.11, \mathrm{P}<0.01$; and for cocaine $(20 \mathrm{mg} / \mathrm{kg})$ : $\mathrm{F}($ dose $)=21.18, \mathrm{P}<0.001]$. The mice given MK-801 $(0.3$ and $1 \mathrm{mg} / \mathrm{kg}$ ) with cocaine ( 10 and $20 \mathrm{mg} / \mathrm{kg}$ ) exhibited lower sensitivities than the mice given saline with cocaine to the challenge-administration of cocaine. Furthermore, the treatment with cocaine $(20 \mathrm{mg} / \mathrm{kg})$ with $\mathrm{MK}-801(1$ 


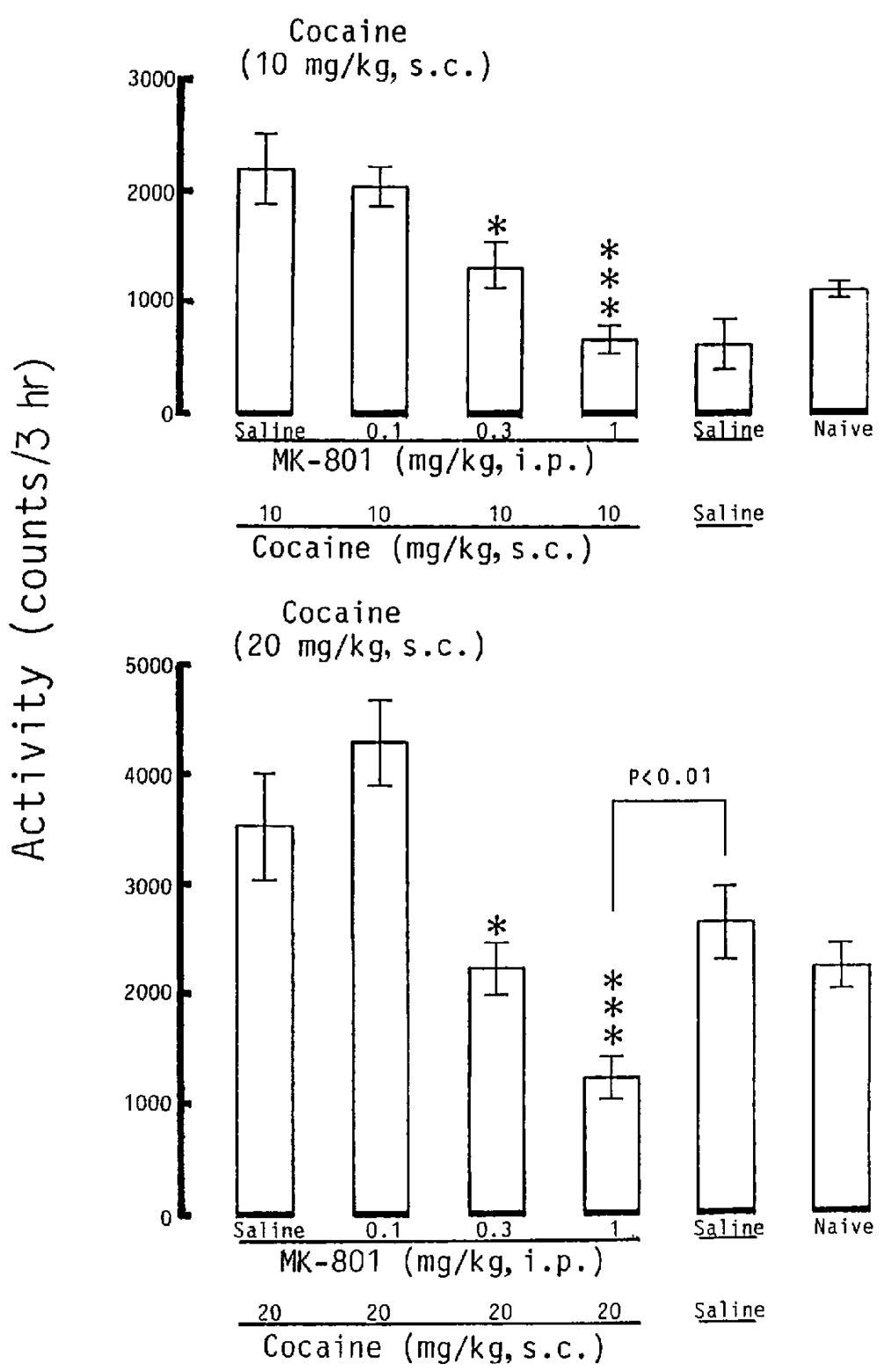

Fig. 6. Overall activity counts for $3 \mathrm{hr}$ after the challenge-administration of cocaine $(10 \mathrm{and} 20 \mathrm{mg} / \mathrm{kg}$, s.c.) to the mice that have been given the repeated 5 -time coadministrations of saline or MK-801 with cocaine (10 and $20 \mathrm{mg} / \mathrm{kg}$, s.c.). The challenge-administration was conducted 7 days after the 5 th coadministration. Values are expressed as the mean \pm S.E. ${ }^{*}$ and ${ }^{* * *}$ : Significantly different from the activity counts of the mice that had been given cocaine alone $(\mathbf{P}<0.05$ and $\mathbf{P}<0.001$, respectively). $\mathrm{N}=9-20$ in each group.

$\mathrm{mg} / \mathrm{kg}$ ) produced significantly lower sensitivity to cocaine than the saline (s.c. and i.p.) treatment.

\section{Effect of repeated treatments with $M K-801$ after cocaine} sensitization

As shown in Fig. 7 , the repeated treatments with cocaine $(20 \mathrm{mg} / \mathrm{kg})$ alone induced sensitization to the ambulation-increasing effect, and the activity counts at the 5th administration were $2-2.5$ times as high as those at the 1st administration. Although MK-801 inhibited the development of cocaine-sensitization in both the pretreatment and coadministration schedules, the established sensitization to cocaine was scarcely modified by the post-treatment with any doses of MK-801.

\section{DISCUSSION}

MK-801, at comparatively low dose, has been reported to facilitate the dopaminergic neurotransmission at the frontal cortex, hippocampus, striatum and reticular for- 


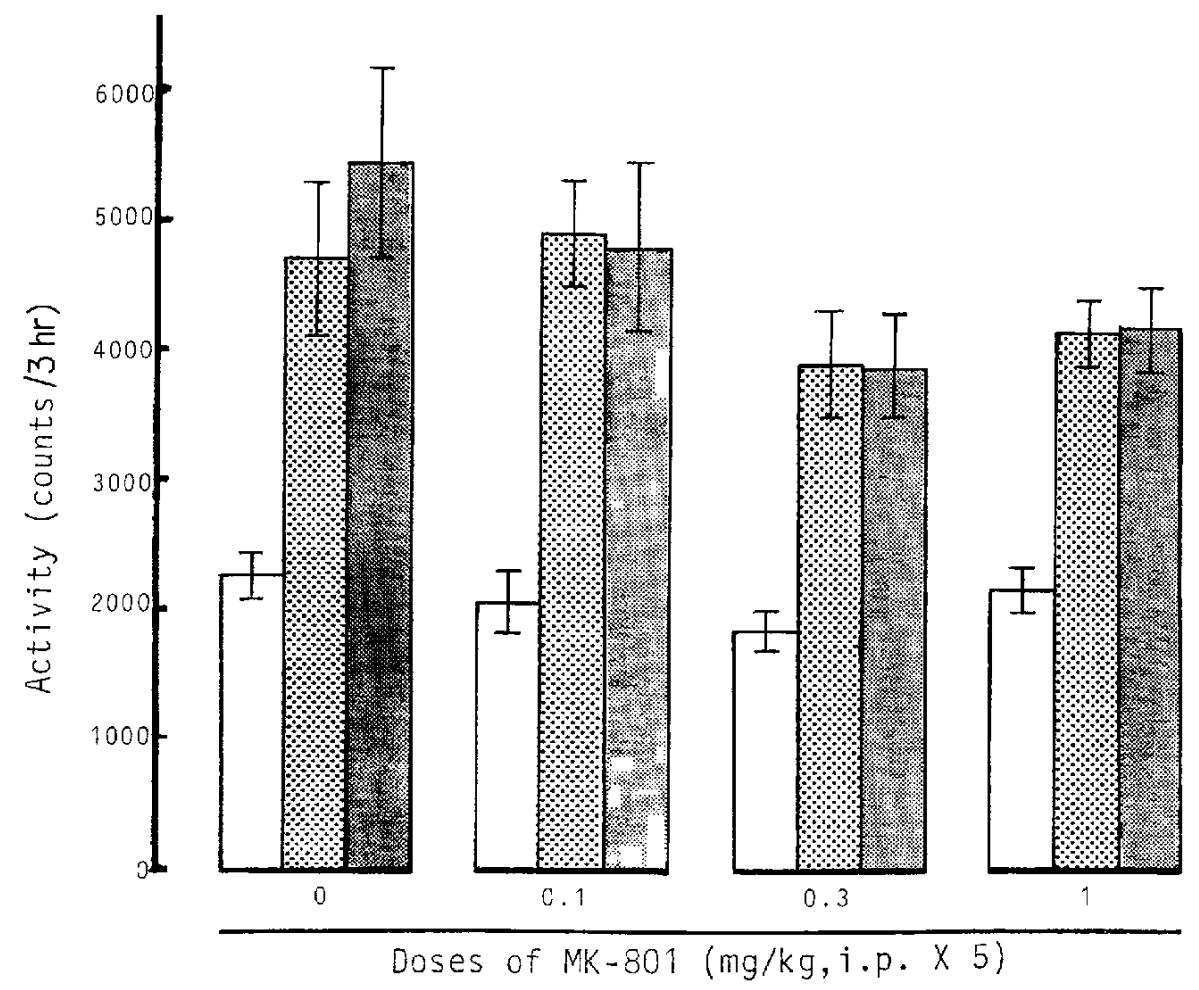

Fig. 7. Effects of the 5-daily treatments with MK-801 (0: saline. $0.1,0.3$ and $1 \mathrm{mg} / \mathrm{kg}$, i.p.) on the sensitization to the ambulation-increasing effect of cocaine $(20 \mathrm{mg} / \mathrm{kg}$, s.c.). The cocaine sensitization was produced by the repeated 5-time administrations of cocaine $(20 \mathrm{mg} / \mathrm{kg})$ at 3- to 4 -day intervals. From the next day after the final cocaine administration, the 5-daily MK-801 treatments were started. Cocaine was readministered 7 days after the final MK-801 treatment. Columns: $\mid$ |, the 1st administration of cocaine; $⿴ 囗 大$, the 5 th administration of cocaine, i.e., immediately before treatment with MK-801; 露, the challenge administration of cocaine after the 5-time treatment with MK-801. Values are expressed as the mean \pm S.E. $N=19-20$ in each group.

mation in terms of brain field potentials in rats (12). Consistent with such data, MK-801 produced behavioral stimulation in mice, which was partially similar to that produced by a dopaminergic agonist such as cocaine and methamphetamine. Furthermore, Clineschmidt et al. (7) reported the CNS stimulant action of MK-801. Thus, a single dose of MK-801 increased the ambulatory activity of mice, and the repeated administration induced a sensitization to the effect. However, the sensitization was produced only at $0.3 \mathrm{mg} / \mathrm{kg} \mathrm{MK}-801$, and the activity count at the 5th administration was only about 1.4 times as high as that at the 1st administration, whereas in the present and previous studies (13), we demonstrated that the repeated administrations of cocaine or methamphetamine produced enhancement in their effects to $1.8-2.5$ times as high as the initial effects. Although MK-801 at 1 $\mathrm{mg} / \mathrm{kg}$ produced a marked ataxia, a gross observation of the mice given MK-801 revealed that it was unlikely that such an effect nonspecifically inhibited the induction of sensitization. We have demonstrated that the characteristics of the ambulation-increasing effect of MK-801 are partially similar, but not identical, to those of metham- phetamine (13). These results suggest that MK-801 produces the ambulation-increasing effect in a manner different from those of CNS stimulants.

Our preliminary study demonstrated that the mice given a single dose of MK-801 did not show any significant change in the sensitivity to the ambulationincreasing effect of cocaine (H. Kuribara, unpublished data). So the interactions between MK-801 and cocaine in the repeated administration schedules were investigated in the present study. The data that were obtained from the challenge-administration of cocaine to the MK-801-administered mice also suggested differential characteristics between MK-801 and cocaine. In the mice repeatedly given MK-801 $(0.3$ and $1 \mathrm{mg} / \mathrm{kg})$, there was no cross-sensitization from MK-801 to cocaine, but rather a decrease in the cocaine-sensitivity was induced. A significant decrease in the sensitivity to methamphetamine was also demonstrated in the MK-801-administered mice, although $1 \mathrm{mg} / \mathrm{kg}$ of MK-801 was required to elicit such an action (13). Thus, MK-801 interacts with cocaine at a lower dose than with methamphetamine. This result may reflect the different ways of activating dopaminergic 
neurotransmission between methamphetamine and cocaine. Methamphetamine activates dopaminergic neurotransmission by facilitating the release and inhibiting the reuptake of catecholamines, whereas cocaine does so only by inhibiting the reuptake.

Karler et al. (14), De Montis et al. (15) and Wolf and Jeziorski (16) reported that MK-801 blocked development of the sensitization to cocaine in rats. Schenk et al. (17) also reported that MK-801 blocked the sensitization to cocaine's reinforcing effect produced by the pre-exposure to methamphetamine. Most of the experimental evidence have implicated the brain dopaminergic systems as the center of cocaine-induced behavioral sensitization (18). In this study, the coadministration of MK-801 with cocaine potentiated the ambulation-increasing effect. However, the mice given the repeated coadministration of MK-801, at 0.3 and $1 \mathrm{mg} / \mathrm{kg}$, with cocaine exhibited significant reduction in sensitization to cocaine. These results are in agreement with previous studies (14-16). A similar interaction was demonstrated between MK-801 $(1 \mathrm{mg} / \mathrm{kg})$ and methamphetamine (13), clearly indicating again that the characteristics of the ambulation-increasing effect of MK801 are different from either those of cocaine or methamphetamine. The effective dose of MK-801 for interaction with cocaine was lower than that with methamphetamine, indicating characteristic differences in the ambulation-increasing effects between cocaine and methamphetamine. Thus, it is considered that the protective action of MK801 is more potent for cocaine sensitization than for methamphetamine sensitization. This consideration may also be supported by the fact that the development of cocaine sensitization was only blocked by dopamine receptor antagonists at doses much higher than the effective doses for methamphetamine (19).

The repeated pretreatment with MK-801 could reduce the sensitivity to cocaine, and the repeated coadministration of MK-801 with cocaine inhibited the development of cocaine-sensitization. However, the cocaine-sensitization once established was not changed by the post-treatment with MK-801. This characteristic of cocaine sensitization was almost the same as that of methamphetamine sensitization, suggesting that MK-801 is effective only for protecting the development of cocaine- and methamphetamine-sensitization, but not for ameliorating the established sensitization. Why did MK-801 fail to ameliorate the established sensitization? One possible explanation is the "conditioning" to the effect of CNS stimulants; that is, repeated experience of behavioral stimulation is involved in the establishment of sensitization.

The sensitization to cocaine or amphetamines in animals has been considered to be closely related to the psychotic states produced by long-term abuse of these drugs; i.e., the induction of cocaine- or amphetamine- psychosis $(10,11)$. It is therefore suggested that the state of easy appearance of a psychotic symptom may be hardly ameliorated by NMDA antagonists after once experience of such a symptom, although NMDA antagonists including MK-801 are expected to be effective for protection against the induction of cocaine- and amphetamine-psychoses.

\section{Acknowledgments}

We thank Professor Yukiteru Machiyama, Department of Neuropsychiatry, Gunma University School of Medicine, for comments on this manuscript; and we also thank Dr. Kazuo Takeuchi, Department of Public Health, Gunma University School of Medicine, for advice on the statistical analyses.

\section{REFERENCES}

1 Wong EHF, Kemp JA, Priestley T, Knight AR, Woodruff GN and Iversen LL: The anticonvulsant MK-801 is a potent $N$ methyl-D-aspartate antagonist. Proc Natl Acad Sci USA 83, 7104-7108 (1986)

2 Foster AC and Wong EHF: The novel anticonvulsant MK-801 binds to the activated state of the $N$-methyl-D-aspartate receptor in rat brain. Br J Pharmacol 91, 403-409 (1987)

3 Simon RP, Swan JH, Griffiths TD and Meldrum BS: Blockade of $N$-methyl-D-aspartate receptors may protect against ischemic damage in the brain. Science 226, 850-852 (1984)

4 Wieloch T: Hypoglycemia-induced neuronal damage prevented by an $N$-methyl-D-aspartate antagonist. Science 230, 681-683 (1985)

5 Clineschmidt BV, Williams $M$, Witoslawski JJ, Bunting PR, Risley EA and Totaro JA: Restoration of shock-suppressed behavior by treatment with (+)-5-methyl-10,11-dihydro-5Hdibenzo $[a, d]$ cyclohepten-5,10-imine (MK-801), a substance with potent anticonvulsant, central sympathomimetic and apparent anxiolytic properties. Drug Dev Res 2, 147-163 (1982)

6 Kuribara H, Fujiwara S, Yasuda $H$ and Tadokoro S: The anticonflict effect of MK-801, an NMDA antagonist: Investigation by punishment procedure in mice. Jpn $J$ Pharmacol 54, $250-252$ (1990)

7 Clineschmidt BV, Martin GE, Bunting PR and Papp NL: Central sympathomimetic activity of $(+)-5$-methyl-10,11-dihydro-5H-dibenzo $[a, d]$ cyclohepten-5,10-imine (MK-801), a substance with potent anticonvulsant, central sympathomimetic and apparent anxiolytic properties. Drug Dev Res 2, 135-145 (1982)

8 Kuribara H, Asami T, Ida I and Tadokoro S: Characteristics of the ambulation-increasing effect of the noncompetitive NMDA antagonist MK-801 in mice: Assessment by the coadministration with central-acting drugs. Jpn J Pharmacol 58, 11-18 (1992)

9 Choi DW: Glutamate neurotoxicity and disease of the nervous system. Neuron 1, 623-634 (1988)

10 Robinson $\mathrm{T}$ and Becker $\mathrm{J}$ : Enduring change in brain and behavior produced by chronic amphetamine administration: A review and evaluation of animal models of amphetamine psychosis. Brain Res Rev 11, 157-198 (1986)

11 Tadokoro S and Kuribara H: Reverse tolerance to the ambulation-increasing effect of methamphetamine in mice as an 
animal model of amphetamine-psychosis. Psychopharmacol Bull 22, 757-762 (1986)

12 Dimpfel W and Spuler M: Dizocilpine (MK-801), ketamine and phencyclidine: Low doses affect brain field potentials in the freely moving rat in the same way as activation of dopaminergic transmission. Psychopharmacology (Berlin) 101, $317-323$ (1990)

13 Kuribara H, Asami T, Ida I, Iijima $Y$ and Tadokoro S: Effects of repeated MK-801 on ambulation in mice and in sensitization following methamphetamine. Psychopharmacology (Berlin) 108, 271 - 275 (1992)

14 Karler R, Calder LD, Chaudhry IA and Turkanis SA: Blockade of "reverse tolerance" to cocaine and methamphetamine by MK-801. Life Sci 45, 599-606 (1989)

15 De Montis MG, Devoto P, Meloni D, Gambarana C, Giorgi G and Tagliamonte A: NMDA receptor inhibition prevents tolerance to cocaine. Pharmacol Biochem Behav 42, 179-182 (1992)
16 Wolf ME and Jeziorski M: Coadministration of MK-801 with amphetamine, cocaine and morphine prevents rather than transiently masks the development of behavioral sensitization. Brain Res 613, 291 - 294 (1993)

17 Schenk S, Valadez A, McNamara C, House DT, Higley D, Bankson MG, Gibbs S and Horger BA: Development and expression of sensitization to cocaine's reinforcing property: Role of NMDA receptors. Psychopharmacology (Berlin) 111, 332 - 338 (1993)

18 Zahniser NR and Peris J: Neurochemical mechanisms of cocaine-induced sensitization. In Cocaine: Pharmacology, Physiology and Clinical Strategies, Edited by Lakoski JM, pp 229-260, CRC Press, Boca Ratou (1992)

19 Kuribara $\mathrm{H}$ and Uchihashi $\mathrm{Y}$ : Dopamine antagonists can inhibit methamphetamine sensitization, but not cocaine sensitization, when assessed by ambulatory activity in mice. J Pharm Pharmacol 45, 1042- 1045 (1993) 